\title{
ESPORTE ESCOLAR NO BRASIL: CONTRADIÇÕES E POSSIBILIDADES
}

DOI 105902/0102830813801

Data de submissão: 12/05/2014

Data de aceite: 29/05/2015

\section{Resumo}

O presente artigo analisa parte da produção teórica do esporte no contexto escolar e a principal política pública do esporte escolar brasileiro ï as Olimpíadas Escolares. Com um propósito crítico, o texto destaca a política do esporte escolar no Brasil e expõe as tensões entre esporte escolar e esporte de rendimento. Por meio de entrevistas estruturadas com professores com ampla experiência em jogos escolares e documentos que orientam a organização destes, reflete as ações contraditórias do evento. Na sequência, problematiza algumas possibilidades de reestruturação da política de esporte escolar no país.

Palavras-chaves: Esporte Escolar. Educação física. Jogos escolares.

\section{INTRODUÇÃO}

O pensamento científico em educação física, especificamente sobre a temática escolar, avançou bastante nas décadas de 1980 e 1990. No que se refere à reforma do pensamento em educação física nessas décadas, coube ao esporte ser o mote e o referencial imperativo de boa parte das produções científicas da área, e foram, as influências das teorias críticas da educação que nortearam como o esporte devia ser tratado enquanto conteúdo hegemônico da educação física. Portanto, foi a crítica ao fenômeno esportivo na educação física a mola propulsora de grande parte da construção de um pensamento pedagógico renovado da área. De todo modo, o avanço do debate da educação física escolar e sua relação com o esporte, visto em importante autores como Oliveira (1983), Castellani Filho (1988) e Kunz (1994), não foi suficiente para arrefecer a lógica esportivista tão presente nas aulas de educação física e, mais ainda, nos espaços dos jogos escolares. 
Não obstante a crítica ao esporte ter sido o agente alavancador das produções reformistas da educação física, boa parte destas construções se deu numa perspectiva de ter no esporte um conteúdo específico das aulas de educação física ou apenas mais um dos vários temas da cultura corporal (SOARES et al, 1992), como é possível perceber no tocante as contribuições de Bracht (1992) e as expressões esporte manòe r̃daòescola e o que isso representou no debate da área; e o que se seguiu com Vago (1996) e a ideia do estabelecimento de uma ñensão permanenteò na relação entre esporte e escola. Embora importantes para o amadurecimento pedagógico da educação física em sua interface com o esporte, tais questões circunscrevem o esporte como conteúdo de aulas. Ademais, tais produções críticas ao esporte valiam-se da efervescência política vivida no período da redemocratização brasileira, o que motivava discursos ideológicos fundamentados num referencial marxista estruturalista, como é possível observar em Bracht (1985) e Cavalcanti (1984). Embora sejam estas importantes elaborações no que diz respeito à ascensão de um discurso crítico na área, é necessário demarcar, que neste novo século, as produções teóricas em educação física continuam esse processo reformista muito mais com ações propositivas e metodológicas do que com as outroras ações denuncistas, no qual o esporte escolar deve ser pautado.

Nesse sentido, cabe questionar como se dão as práticas esportivas representadas pelas escolas? Como o Estado compreende este direito, legitimando isso através da organização de eventos competitivos (ou não) entre as escolas? Que sentido político existe no fomento desses eventos? E como é percebido por quem participa? Refletir sobre estes questionamentos é o fito deste artigo, todavia longe de tentar responder com total propriedade tais perguntas, mas com o anseio de ascender o debate em torno do esporte não apenas restrito às aulas de educação física, mas também como possibilidade legítima de práticas educativas de intercâmbios entre os escolares. A fim de atender a este objetivo, encaminham-se os resultados de pesquisa que deu voz a alguns atores diretamente envolvidos com os atuais Jogos Escolares no Brasil. No texto, breves esclarecimentos históricos e contemporâneos dos Jogos bem como o tenso debate crítico da educação física em torno do esporte precede a interlocução com três professores de educação física que possuem larga experiência empírica no âmbito do esporte escolar. Os registros das impressões desses personagens, coadunadas à produção teórica da área e os rumos da política brasileira nesse setor, dão indícios de uma presente contradição. Por fim, o texto 
Esporte Escolar no Brasil: Contradições e Possibilidades

encerra-se com uma reflexão sobre as possibilidades de mudanças a partir do contexto da própria escola.

\title{
BREVE HISTÓRIA DOS JOGOS ESTUDANTIS BRASILEIROS E SUA RELAÇÃO COM O SISTEMA ESPORTIVO NACIONAL
}

Os primeiros Jogos Estudantis Brasileiros ocorreram em 1969, por iniciativa do Ministério da Educação e Cultura, na cidade de Niterói, no Rio de Janeiro, e contaram com a participação de sete estados, representados por 315 estudantes. Os anos seguintes dos jogos viram um crescimento da participação das unidades da federação em escala geométrica, o que levou 4480 ï entre atletas e dirigentes - à Brasília no ano de 1973. (ARANTES; MARTINS; SARMENTO, 2012)

Os Jogos Estudantis Brasileiros (JEB̂̂) se perpetuaram ao longo das décadas de 1970, 1980 e 1990. Sua estrutura de competição era, basicamente, uma cópia fiel dos eventos esportivos organizados internacionalmente como as Olimpíadas e os Jogos Panamericanos. Enquanto as representatividades nesses eventos se dão pelos países e suas seleções nacionais, nos JEB⿳亠丷, a representação se dava pelos estados da federação brasileira. Cada estado reunia a nata dos melhores atletas $\ddot{i}$ ainda estudantes secundaristas ï para representá-lo nos jogos. Para Bracht (2003, p.91), o corolário desse formato dos jogos apresentava os seguintes termos:

\begin{abstract}
Estabeleceu-se uma relação de mútuo condicionamento: ao componente curricular educação física é colocada a tarefa de funcionar com alicerce do esporte de rendimento sendo considerado a base da pirâmide; e a instituição esportiva, com o discurso da saúde e da educação, lança mão desses argumentos para conseguir apoio e financiamento público e alcançar legitimidade social.
\end{abstract}

A ñpirâmideòa qual Bracht (2003) faz referência é a figura que expressa o modelo de orientação desigual no processo de estruturação esportiva brasileira, no qual se legitima a contradição de necessariamente fomentar o esporte de base ï leia-se com escolares ï com a finalidade exclusiva de sustentar a suposta excelência de uma minoria (pico da pirâmide) que de fato se projeta para o esporte de alto rendimento.

Reforçando esta análise, Castellani Filho (2001) relembra o inciso II do artigo 217 da Constituição Federal de 1988, que trata da destinação dos recursos públicos para a promoção prioritária do desporto educacional e, apenas em casos específicos, para o desporto de alto rendimento. Portanto, como os eventos do esporte escolar são 
genuinamente marcados pelo viés do esporte de rendimento, poder-se-ia entender como redundante ï pelo menos na prática ï a execução do texto da lei.

O discurso dos autores acima reforça a compreensão de que, naquele momento histórico, o Estado brasileiro iniciava uma política de fomento ao esporte escolar, porém, balizado ante as características do esporte de rendimento, pelo menos no que diz respeito a sua estrutura macro. Atualmente, esta estrutura permanece quase que imutável, embora se desdobre numa nova organização. É o que se pretende verificar a seguir.

\section{OLIMPÍADAS ESCOLARES: UMA POLÍTICA PÚBLICA DE GESTÃO (INTERFERÊNCIA) PRIVADA}

O ano de 2000 marca o início da transformação macro-estrutural dos jogos estudantis brasileiros. Naquela ocasião, a proximidade do Ministério da Educação com o Comitê Olímpico Brasileiro (COB), propiciou a criação de uma comissão organizadora dos jogos formada por representantes do Ministério da Educação, do Ministério do Esporte e Turismo, do $\mathrm{COB}$ e da Rede Globo de televisão. Esta comissão conseguiu consolidar a reforma do evento nacional esportivo escolar, e, em sua primeira versão ainda no ano 2000, foi denominada de ñ Olimpíada Colegial Esperançaò

A principal mudança do evento surgiu ante a representatividade estadual e o acréscimo de mais uma categoria aos jogos. Antes, portanto, os estados levavam ao encontro uma seleção estudantil ï no caso dos esportes coletivos ï e neste novo formato a representação se daria por instituição escolar, ou seja, era assegurada uma vaga por federação nas Olimpíadas Colegiais, e tal vaga seria preenchida pela instituição de ensino que lograsse êxito (campeã) nos jogos escolares municipais e posteriormente os estaduais. No que diz respeito às categorias, os novos jogos seriam ofertados para duas faixas distintas, sob o entendimento de se estar contemplando os níveis de ensino fundamental (12 a 14 anos) e de ensino médio (15 a 17 anos).

A favor das mudanças, argumentava-se o caráter muito mais democrático de acesso aos jogos, já que na versão anterior ï a do JEB`s ï a representatividade se dava de maneira completamente seletiva e agora, ao contrário, oportunizaria a todos aqueles, que não tendo condições de compor o plantel de uma seleção estadual, poderem integrar a equipe da escola (campeã) que viesse a representar seu estado na competição nacional. ñEm 2010, o Comitê Olímpico Brasileiro (COB) identificou o envolvimento de dois milhões de jovens nas 
Esporte Escolar no Brasil: Contradições e Possibilidades

fases municipais e estaduais classificatórias para a fase nacional dos jogosò (ARANTES; MARTINS; SARMENTO, 2012, p. 921).

Com a aquiescência do Ministério do Esporte e do Ministério da Educação, foi delegada ao COB a responsabilidade de organizar o evento que, através de parceria com a Rede Globo de Televisão, conseguiria consequentemente uma maior divulgação dos jogos, possibilitando a obtenção de novas receitas provenientes da iniciativa privada. É diante dessa conjuntura que se pôde observar a continuidade da associação do esporte escolar como integrante do sistema esportivo nacional, só que agora, numa nova roupagem, com contornos em consonância às demandas globalizadas do esporte de rendimento, em que a necessidade de tratá-lo como produto passa pela sua própria sobrevivência. Bracht (2003). Outrossim, a reforma na estrutura e na gestão dos jogos distancia à responsabilidade pública no fomento do esporte escolar, na mesma medida em que o aproxima dos interesses privados.

\section{SOBRE AS TENSÕES DO ESPORTE NA EDUCAÇÃO FÍSICA}

Historicamente o esporte se enraizou como conteúdo fundamental da educação física e isto se deu em função, como pensa Castellani Filho (1988), de que a educação física foi concebida no currículo escolar sob a forma de atividade, reforçando uma compreensão mecânica e dando sentido a uma educação do físico. Na escola, a educação física tratou do esporte caracterizando-o e priorizando sua dimensão técnico-competitiva. Ademais, de acordo com Bracht (2000, p.15) é importante ressaltar que o esporte foi assimilado pela educação física por acordar com o seu objetivo previsto em lei, que era o de desenvolver a aptidão física e o caráter moral (civismo) do indivíduo, porém ñpaulatinamente, o esporte se impõe à educação física, ou seja, instrumentaliza a educação física para o atingimento de objetivos que são definidos e próprios do sistema esportivoò Tal fato, nas décadas de 1960 e 1970, foi considerado como fator que valorizava o componente curricular, entretanto, também trazia consigo, ou pelo menos reforçava a idéia de que na escola, a educação física era na verdade apenas uma extensão do esporte.

Apenas na década de 1980, ganha força um pensamento crítico e reformador da educação física frente ao esporte como conteúdo hegemônico de seu currículo, bem como novas percepções de como o esporte poder-se-ia ser percebido e praticado na escola. Logo, asseverou-se a crítica ao esporte entendendo que suas inexoráveis regras e técnicas aprisionavam a expressividade do corpo (VAZ, 2001). A crítica se balizou a partir de um 
movimento político-ideológico de esquerda e que, em determinado momento, nas décadas de 1980 e 1990, fomentou um discurso contrário ao esporte, chegando a ganhar contornos de radicalismo, condenando a presença r̃do princípio do desempenho no esporteò (VAZ, 2001, p.88), chegando até mesmo a atribuir ao próprio esporte a culpa deste princípio.

Bracht (2000) é um dos autores que reforçou este pensamento e propiciou uma profícua colaboração no desenvolvimento do debate, contudo, parece se ressentir do rótulo que embutiu nesse movimento reformista da área ï da negação do esporte como possibilidade de ação da educação física na escola. Sobre isso, procura esclarecer alguns mal entendidos. Um deles seria o problema da compreensão de que quem critica o esporte é contra o esporte. Para o autor, existe uma visão maniqueísta do problema e isso ganha força no debate acadêmico contemporâneo, debate travado por aqueles que são a favor do esporte e os que são contra o esporte. Esclarecendo, diz que r̃a negação do esporte não vai no sentido de aboli-lo ou fazê-lo desaparecer ou então, negá-lo como conteúdo das aulas de educação física. Ao contrário, se pretendemos modificá-lo é preciso exatamente o oposto, é preciso tratá-lo pedagogicamente. (BRACHT, 2000, p.16)

Outro mal entendido, segundo Bracht (2000, p.16) é o de que r̃quem trata criticamente o esporte nas aulas de educação física são contrários ao ensino das técnicas esportivasò e com isso, seria possível perceber mais uma contraposição maniqueísta no debate, agora visto como os tecnicistas e os não-tecnicistas. Sobre isso, advoga para a compreensão que se deve ter frente à finalidade da técnica, que é a de permanecer sempre a serviço do homem. T̃ que é fundamental perceber é que a técnica é sempre meio para atingir finsò (BRACHT, 2000, p.16). No esporte $і ̈$ de rendimento ï isso não ocorreria em função dos seus objetivos comprometidos com o resultado esportivo, e nesse caso, o homem seria levado a permanecer subordinado às técnicas esportivas. Sobre o esporte de rendimento, o autor ainda enfatiza que suas ações estão sempre sendo julgadas e valorizadas de acordo com o resultado final, observando a performance e a eficiência como parâmetros de qualidade. Logo, é importante ressaltar que r̃ que se criticou e se critica então, é a subordinação inconsciente não à técnica enquanto tal, mas à finalidade a qual determinada técnica está a serviçoò(BRACHT, 2000, p.17).

Embora tais discursos em torno da questão do esporte e da educação física tenham avançado no sentido crítico e reformista das práticas, grande parte delas permanecem estancadas no aparato curricular. Como se não fosse importante retratar o esporte numa esfera extracurricular, que historicamente sempre esteve arraigado à escola. Entendemos 
Esporte Escolar no Brasil: Contradições e Possibilidades

que a quantidade das produções que referenciam o esporte à educação física curricular ï e que aqui se mostram num pequeno prolegômeno $i ̈$ alcançou um estágio maduro do ponto de vista científico e que, as novas produções, se atentarão frente aos novos anseios e desafios. Contudo, incomoda o desprezo por estudos que consideram o esporte presente na escola como elemento cultural e complementar à formação do aluno. Caso não haja desprezo, é consenso perceber que se encontram incipientes os estudos que agregam e compreendem de maneira legítima a presença do esporte na escola. Fato reforçado pela quase ausente linha de pesquisa nos programas de pós-graduação que eventualmente poderiam visualizar o esporte escolar como contexto importante de pesquisa na educação física. A escassez tem a ver com a força crítica dos argumentos contrários ao esporte de rendimento. Se por um lado a crítica deu novos rumos à educação física escolar, por outro provocou, inconscientemente (ou não), alguns efeitos colaterais. Todavia, talvez a sensatez esteja no discurso de Lovisolo (2001, p.110): meste sentido, importa menos aquilo que o esporte de rendimento é na sociedade e muito mais o que fazemos com ele no processo educacionalò

\section{DELIMITAÇÕES METODOLÓGICAS DO ESTUDO}

Com o intuito de obter informações específicas sobre as Olimpíadas Escolares, no que tange a suas características conjunturais internas, bem como suas nuanças relativas a seus participantes, elaborou-se um conjunto de entrevistas a serem aplicadas com três professores que participaram de vários eventos, desde o ano 2000. Registra-se que os professores assinaram o Termo de Consentimento Livre e Esclarecido e que o projeto de pesquisa foi aprovado por Comitê de Ética e protocolado no número 029/2012. A escolha de entrevistar estes professores deveu-se ao entendimento de que a grande experiência vivida por eles diretamente em eventos escolares esportivos, sobretudo nos eventos nacionais $\ddot{i}$ as Olimpíadas Escolares - conduziria com legitimidade ao objeto de análise, embora não haja a pretensão de que as falas dos sujeitos entrevistados e objetivadas em dados de pesquisa sirvam para ilações ao debate ou generalizações científicas. A organização da elaboração desse instrumento de pesquisa seguiu a orientação e o entendimento de Severino (2007, p.125) no correspondente a constituição da técnica de entrevista estruturada. Para este autor a entrevista estruturada r̃são perguntas direcionadas e previamente estabelecidas, com determinada articulação internaò no qual procura, a partir de uma diretividade intencional, respostas que otimizem o tratamento das informações na construção de categorias. Em 
função dessas características, o estudo circunscreve-se a partir de uma perspectiva qualitativa de abordagem analítico-descritiva.

Na sequência do texto, os professores são referenciados por letras maiúsculas I, C e D. As letras indicam as inicias de sua relação de atuação no esporte escolar. A letra ñò identifica o professor que atua com a modalidade de esporte individual, no caso o atletismo. Este professor é exclusivo da Secretaria de Educação do Distrito Federal (SEDF) embora não atue em escola, mas num complexo esportivo especificamente mantido para atender demandas do esporte escolar. Possui experiência de mais de 20 anos no esporte e trabalha no contexto do esporte escolar desde 1990. Sua formação em educação física se deu durante a década de 1980. O professor ñCò referencia o professor que atua com esporte coletivo, qual seja o basquetebol. Este teve sua formação acadêmica também na década de 1980, tentando se aprofundar, ao longo de sua trajetória universitária, nos estudos do treinamento esportivo. Está há 14 anos trabalhando com o esporte escolar. Conhece a estrutura do antigo JEB $\hat{\Phi}$ por ter feito parte da equipe que organizava os jogos escolares do Distrito Federal no início da década de 1990. Trabalha há 15 anos numa escola privada que tem tradição em fomentar o esporte escolar e, por isso, pôde desenvolver trabalhos que o conduzisse à participação em todos os eventos escolares nacionais, desde 2000, como representante do DF nesses eventos. O professor identificado pela letra C̃ò é atualmente, dirigente esportivo na organização dos Jogos Escolares do DF. Tem experiência como professor-técnico na modalidade de basquetebol e também possui experiência em jogos escolares no âmbito regional e nacional. Sua formação ocorreu durante a década de 1990.

Findado as entrevistas, o material recolhido de quase duas horas de gravação foi integralmente degravado para posterior análise. Os dados foram organizados em três agrupamentos genéricos, que destacavam informações acerca da relação esporte e educação/educação física, informações específicas sobre política de esporte escolar e Olimpíadas Escolares e por fim, informações que apresentavam exemplos e histórias vividas pelo interlocutor.

Além dos dados obtidos pelas entrevistas, algumas informações importantes foram extraídas a partir de análise documental. Para Severino (2007) os documentos são fontes importantes de pesquisa embora não tenham passado por nenhum outro tratamento analítico. Em nosso caso foram realizadas análises de documentos de regulamentos específicos das Olimpíadas Escolares bem como matérias de jornais e mídia eletrônica que 
Esporte Escolar no Brasil: Contradições e Possibilidades

serviram de fontes para algumas reflexões, embora não apareçam textualmente no presente artigo.

\section{ESPORTE ESCOLAR: POR UMA PRÁTICA COM SENTIDO EDUCACIONAL}

A realidade histórica e contemporânea sobre a percepção do esporte escolar no Brasil é caracterizada pela lógica da maximização do desempenho esportivo. Portanto, é mister buscar novos rumos para o esporte escolar sob pena de se assim não o fizermos, corrermos o risco de ter seu espaço tomado inteiramente pelo esporte de rendimento. A propósito deste estudo, por meio de fragmentos das entrevistas realizadas, remetemos alguns entendimentos e práticas docentes com sentido de tratar o esporte de maneira pedagógica, não no que diz respeito as suas práticas técnicas, mas as suas ações intencionais subjetivas.

Apesar de genérico, o professor $\mathrm{C}$ demonstra compreender o sentido da estreita relação entre esporte e educação, ao mesmo tempo em que consegue enfatizar as preocupações que se deve ter a guisa de refletir sobre as contradições que em alguns momentos o esporte pode apresentar, principalmente quando é mal orientado a quem se destina a sua prática, estando comprometido com o ganhar a qualquer custo. Sobre isto, discursa o professor:

ó esporte é a educação. Ele não pode estar dissociado em nenhum momento (...), é um meio fantástico de se educar. Porque ele tem dentro dele (...) a questão da motivação. Uma pessoa interessada (...) vai se desenvolverô (PROFESSOR C).

ó(O esporte) não colabora (para a educação) quando ele impõe a questão da vitória a qualquer custo (...), quando você tem alguém que trabalha na sua equipe, que para vencer eu possa pegar alguém fora da idade e possa acrescentar ele naquele grupo, porque ali ele vai se sobressair(...). Quando você pega aspectos frágeis de um adversário para poder explorar no sentido negativo mesmo... ñ olha, fulano tá mancando da perna, se você der um encostão na perna dele é possível que ele não consiga terminar o jogo. (...) nesse aspecto ele (o esporte) foge do que eu compreendo como educação, como formação (...) preparar o ser humano pra vidaô (PROFESSOR C). 
Sobre a virtude no âmbito da motivação que permeia a prática esportiva, corrobora Lovisolo (2001, p. 112) e acrescenta que só gostamos dos esportes pois eles nos divertem e nos emocionam, m̃os tiram do tédio muito mais do que ajudam a evadir-nos da realidadeò Daí a confirmação que o esporte, por mover internamente o indivíduo, deva ser tratado como instrumento educacional, mesmo se tratando de um sentido generalista. Além disso, reforçanos a percepção da compreensão do professor ante o compromisso ético na formação do indivíduo. Na verdade, o que o professor aponta são aspectos da realidade que sempre permeou o esporte de rendimento mas não tem nenhum sentido educacional devendo ser execrado da esfera escolar. O mesmo professor (C) reforça esses fatos recordando-se de um exemplo vivenciado:

ó já vi um atleta, pronto pra entrar em quadra e o técnico dele pedir a ele que troque de uniforme, que empreste até o tênis, porque o atleta que chegou joga melhor do que ele e, aquele garoto que chegou na hora, que se comprometeu com tudo, tava até aquecido pra jogar, teve que abrir mão do uniforme, até do próprio tênis, porque o outro tava sem, (mas) tecnicamente é melhor e pode entrar em jogo e talvez vencer (...)â (PROFESSOR C).

É lamentável que isto ocorra. Imaginemos quantos garotos passaram (sofreram) m̃a mãoòdeste professor. Apesar de indignante, importante seria não atribuir esse incidente ao esporte. Tal fato indica que o professor só enxerga o resultado, a vitória, custe o que custar, pouco importa constranger uma criança ou um jovem.

Recorro novamente às palavras de Lovisolo (2001): a de nos preocuparmos com o que estamos fazendo com esporte no processo educacional. Esta trata-se de uma péssima atitude, mas existem outras possibilidades. Observando o mesmo exemplo e tentando dar à situação uma conotação educacional: o aluno que se atrasou ouviria do professor, mesmo sob o risco de perder o jogo, que ele não mais poderia jogar aquela partida, mas que seria importante sua presença no banco ou na arquibancada. Ao término da partida, caso houvesse tempo, seria possível problematizar para o grupo e também individualmente com o aluno atrasado sobre as conseqüências da falta de responsabilidade e a importância dela para o crescimento pessoal. Grosso modo, isto seria uma ação de caráter educativo.

$\mathrm{Na}$ esteira desse mesmo exemplo, o professor I observa que, no contexto do esporte em que milita, fatos como esses são recorrentes no que diz respeito à cobrança excessiva exercida por professores que focalizam em seu trabalho o máximo rendimento, a busca por 
Esporte Escolar no Brasil: Contradições e Possibilidades

recordes que $\ddot{i}$ no entendimento dele $і ̈$ estão condicionados ao esforço e a dedicação do aluno-atleta. Tal visão pode ser observada em parte na pesquisa de Torre; Albino e Vaz (2007), que ao acompanharem equipes de escolares em Florianópolis (SC) categorizaram os castigos, as punições e os sacrifícios como fórmulas de emulação para a dureza. A expressão da r̃urezaò macula definitivamente os processos de ludicidade em torno da prática esportiva entre os escolares.

Ademais, alerta o professor I, há também o problema de certa frustração do professor que não conseguiu lograr êxito no contexto do esporte de rendimento:

ñA meu ver existem muitos professores que só fazem isso porque entendem que esta é uma forma deles viverem aquilo que gostariam de ter vivido e não viveram por causa da concorrência no esporte e também das condições do esporte aqui no DF (...) aí muitas coisas que eles acreditam que dão certo com adultos eles também fazem com os alunos (...) as vezes acabam sendo desrespeitosos com os alunos(...)â (PROFESSOR I).

Tais relatos materializam um pouco as distorções do esporte, algo que nos parece recorrente no contexto do esporte escolar e que precisa ser problematizado com os professores que trabalham na área e também na formação de novos professores a fim de romper definitivamente com esta lógica que nada apresenta de elementos educativos.

Visto isso, dir-se-ia que o maior evento esportivo estudantil do país está amparado num arcabouço recheado de contradições. Criticava-se o antigo formato dos jogos por perceberem não um evento entre escolas, mas uma competição entre seleções estaduais de federações com jovens em faixa etária estudantil. Porém, no novo formato, mesmo se tratando de um encontro esportivo entre escolas, o que se vê é um apêndice das organizações competitivas do esporte de rendimento. $O$ entendimento do próprio presidente do COB, o Sr. Carlos Arthur Nuzman versa sobre a expectativa de encontrar novos talentos, corroborando a idéia de que o evento existe para suprir de maneira prática a demanda da base da pirâmide esportiva anteriormente aqui explicitada.

O regulamento geral das Olimpíadas Escolares traz em seu artigo $2^{\circ}$, que trata da justificativa, que através das atividades desportivas, crianças e jovens constroem seus valores, seus conceitos, socializam-se e, principalmente, vivem as realidades. Concordo plenamente com esta assertiva e por isso a preocupação premente de observar como são realizadas tais atividades desportivas no âmbito da escola. Segundo o professor C, no que 
tange às competições, o que se observa é a permanência de uma estrutura regimental em consonância com as características do alto rendimento.

Poucas adaptações foram feitas para aproximar o esporte a uma concepção pedagógica mais aceitável. Uma delas ï a única por sinal ï a da obrigatoriedade da participação efetiva dos alunos durante os jogos das modalidades coletivas. Portanto, exigese que o aluno, inscrito na súmula de jogo, participe no mínimo de um tempo préestabelecido em regra a fim de evitar que os professores com o intuito apenas da vitória, privilegie em jogo aqueles que tenham melhor proficiência esportiva, excluindo outros sujeitos da prática direta da modalidade. É possível considerar esta ação como um avanço rumo a uma prática esportiva de cunho competitivo que estabelece ligações com objetivos educacionais, aproximando-a do contexto que se requer do esporte escolar.

Contudo, outros aspectos ganham destaque negativo, ainda nesta perspectiva das regras dos jogos. Nesse sentido, discursa nosso entrevistado:

ó(...) a estrutura é montada para que você tenha que vencer e de uma diferença muito grande de pontos, você não pode depender de nada, de nenhum outro resultado, senão você não chega as finais do campeonato (...) então se eu lá encontro uma equipe fraca pra jogar, eu tenho que massacrar aquela equipe se eu quiser preservar o meu direito de chegar as finais (...)ô (PROFESSOR C).

No caso, o professor refere-se ao critério de desempate entre as equipes durante a fase de classificação, que incentiva a atitude de estabelecer, se possível, um ñmassacreò com relação ao placar de jogo. Isto ocorre devido ao regulamento dos esportes coletivos das Olimpíadas Escolares, que privilegia demasiadamente o índice técnico em detrimento do viés pedagógico, esquecendo completamente o contexto do esporte escolar, que se deve pautar por uma disputa saudável, em que a busca pela vitória, mesmo sendo legítima, passe sem a necessidade de sobrepujar o adversário de maneira a arriscar poder humilhá-lo.

Remetendo isto a justificativa explícita acima, seria importante refletir que tipo de valores nossas crianças e jovens estariam construindo frente a esta realidade? Como projetarão tais experiências em seu futuro? Logo, é certa a constatação da necessidade de reformar a estrutura dos jogos.

Ademais, esta mesma estrutura que ocorre na esfera nacional gera uma longa cadeia reprodutiva em termos organizacionais dos jogos no âmbito local e regional. É isto que 
Esporte Escolar no Brasil: Contradições e Possibilidades

declara o professor D que enfatiza a sujeição das atividades dos jogos escolares em sua coordenação de dirigente regional observando os critérios das Olimpíadas Escolares, frente à justificativa de preparar melhor os alunos-atletas:

óPrecisamos seguir as regras do nacional porque precisamos aumentar o índice técnico da competição e acreditamos que fazendo isso aqui iremos em breve melhorar nossos resultados (...)ô (PROFESSOR D).

Aspectos como esses reforçam a contradição. Aludem ao problema de que o padrão do rendimento é o elemento central da gestão do esporte escolar, algo que foge ao propósito de uma perspectiva educativa, que por sua vez, deveria ser a expressão máxima dos jogos. O estudo de Millen Neto; Ferreira e Soares (2011) explicam essa opção observando que as escolas veiculam sua imagem aos ñbonsò resultados esportivos em detrimento do desenvolvimento integral dos estudantes, fato que inclusive promove impacto nos aspectos curriculares da educação física na escola.

Caberia então o questionamento de qual é o principal objetivo dos jogos escolares quando a assumimos que o ñndice técnicoò é o principal parâmetro estruturante da organização de nossos jogos? Certamente não é a preocupação com os resultados eminentemente educacionais.

\section{CONSIDERAÇÕES FINAIS}

O Estado brasileiro se depara, nesse novo século, com a premente necessidade de desenvolver políticas que redimensionem o esporte em conformidade aos objetivos da escola. O embate fatalmente se dará frente à força da indústria esportiva e dos meios de comunicação de massa, que, em prol de um empreendimento mercadológico, visam se apropriar do esporte escolar tentando aproximá-lo do esporte em sua manifestação especutacularizada, prisioneiro de um padrão subordinado ao rendimento máximo.

Portanto, é preciso iniciar um processo de reformulação das políticas públicas que versam sobre os Jogos Escolares. Talvez, começando internamente nas escolas. Muitas delas possuem ñogos internosò Porque não experienciar novas formas de disputa, onde o rendimento ótimo seja aquele que é o possível alcançar, sem as pressões da máxima eficiência. No qual as regras possam ser transformadas de acordo com o interesse e a necessidade dos participantes, e que, sobretudo, ajude a otimizar a participação de todos, objetivando a cooperação e a solidariedade. Fazer da competição, a busca salutar de ir em 
direção a uma excelência pessoal e coletiva, ao invés da conotação sobrepujante da vitória a qualquer custo. Nesse sentido, a escola precisa definitivamente romper com um modelo que apenas reproduz a forma com que o esporte tem se vinculado na sociedade, procurando se possível, idealizar novas práticas esportivas que por sua vez, serão catalisadoras de um processo de mudança de concepção de esporte. Ou seja, espera-se que o esporte escolar promova em seus praticantes, a máxima de fazer o sujeito continuar no esporte a partir de uma perspectiva de lazer e, que a ideia do rendimento, não seja um caminho único.

À luz dessas possibilidades, seria interessante que de maneira propositiva, houvesse experiências que pudessem ser relatadas. Certamente o ganho formativo aos escolares seria enorme. Entretanto, o que se sucede nos jogos escolares em todo o país, é a reprodução simples das competições esportivas tradicionais, iguais a que vemos todos os dias na mídia. Pior é saber que, depois de completar 40 anos, o grande evento nacional do esporte escolar brasileiro ï outrora chamado Olimpíadas Escolares e hoje (a partir de 2013) de Jogos Escolares da Juventude ï perpetua-se alicerçado numa estrutura que não acompanha as concepções pedagógicas mais progressistas na área da educação física e do esporte.

\section{Referências}

ARANTES, A; MARTINS, F; SARMENTO, P. Jogos Escolares Brasileiros: reconstrução histórica. Revista Motricidade, Vila Real - Portugal, v. 8, n. S2, 2012, p. 916-924.

BRACHT, V. A criança que pratica esporte respeita as regras do jogo... capitalista. Revista Brasileira de Ciências do Esporte, Campinas, n. 7, v. 2, 1986, p. 62-68.

p. 14-24, 2000.

Esporte na escola e esporte de rendimento. Movimento, Porto Alegre/RS, v. 6 no 12 ,

A política de esporte escolar no Brasil: a pseudovalorização da educação física.

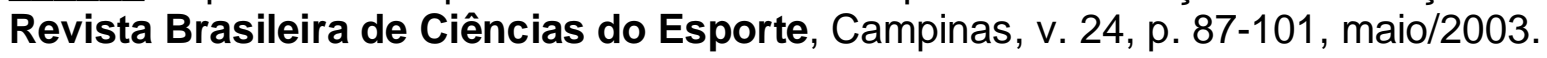

CASTELLANI FILHO, L. Educação física no Brasil: a história que não se conta. Campinas/SP: Papirus, 1988.

Notas para uma agenda do esporte brasileiro. In: CÂMARA DOS DEPUTADOS (Org.). Desafios para o século XXI: coletânea de textos da 1ํㅡㄹ Conferência Nacional de Educação, Cultura e Desporto. Brasília: Coordenação de Publicações, 2001, p. 577-589. 
Esporte Escolar no Brasil: Contradições e Possibilidades

CAVALCANTI, K. B. Esporte para todos: um discurso ideológico. Rio de Janeiro: Ibrasa, 1984.

KUNZ, E. Transformação didático-pedagógica do esporte. ljuí: Unijuí, 1994.

LOVISOLO, H. Mediação: esporte rendimento e esporte da escola. Movimento, Porto Alegre/RS, v.7 № 15, 2001.

MILLEN NetO, A. R.; FERREIRA, A. C.; SOARES, A. J. G. Políticas de esporte escolar e a construção social do currículo de educação física. Motriz. Rio Claro/SP, v.17, n.3, p. 416423, jul./set. 2011.

OLIVEIRA, V. M. O que é educação física. São Paulo: Brasiliense, 1983.

SEVERINO, A. J. Metodologia do trabalho científico. 23. ed. São Paulo: Cortez, 2007.

TORRE, D; ALBINO, D. S.; VAZ, A. F. Sacrifícios, sonhos, indústria cultural: retratos da educação do corpo no esporte escolar. Educação e Pesquisa. São Paulo/SP, v.33, n.3, p. 499-512, set./dez. 2007.

VAGO, T. M. O esporte m̃aòescola e o esporte r̃daòescola: da negação radical para uma relação de tensão permanente. Um diálogo com Valter Bracht. Movimento, Porto Alegre/RS: ano III, n. 5, p. 4-17, 1996.

VAZ, A. F. Técnica, esporte, rendimento. Movimento. Porto Alegre/RS: v.7 n.14, 2001.

\title{
SCHOOL SPORTS IN BRAZIL: CONTRADICTIONS AND POSSIBILITIES
}

\begin{abstract}
This paper analyzes the theoretical production of the sport in the school context and the main Brazilian public policy for sports in school - the School Olympic Games. With a critical purpose, the paper outlines the Brazilian sport in school policy and discusses the tensions between sport in school and the performance sport. Interviewing teachers with extensive experience in sport in school and reviewing documents that guide the organization of this activity, its reflect the event contradictory actions, discussing possible options for restructuring the country policy for sport in school .
\end{abstract}

Keywords: School Sports. Physical education. School games.

DEPORTE ESCOLAR EN BRASIL: CONTRADICCIONES Y POSIBILIDADES 
Resumen: Este artículo analiza la producción teórica de deportes en el contexto escolar y la principal política pública de deportes para escolares de Brasil - los Juegos Olímpicos escolares. Con un propósito crítico, el documento describe la política de deporte escolar en Brasil y analiza las tensiones entre el deporte escolar y el rendimiento deportivo. Utilizando entrevistas con profesores con amplia experiencia en deportes escolares y documentos que orientan a la organización de estos y refleja las acciones contradictorias del evento. A continuación, se analizan las opciones posibles para la reestructuración de la política de deporte escolar en el país.

Palabras clave: Deporte escolar. Educación física. Juegos escolares. 